\title{
PEDREIRA DA ILHA DO CATALÃO: REGISTRO COMPLETO DE UMA MINERAÇÃO ESQUECIDA NA BAÍA DE GUANABARA (RJ)
}

\author{
Renato Rodriguez Cabral Ramos ${ }^{1}$, Claudio Luiz Almeida Vieira Filho ${ }^{2}$, Kátia Leite Mansur ${ }^{3}$, Luis \\ Paulo Vieira Braga ${ }^{4}$, Douglas Renato da Silva ${ }^{2}$ \\ 1 - Geólogo, Professor do Dep. de Geologia e Paleontologia do Museu Nacional, UFRJ; 2 - Estudante de Geologia, Dep. Geologia IG, UFRJ; \\ 3 - Geóloga, Professora do Dep. Geologia IG, UFRJ; 4 - Matemático, Professor do Dep. Geologia IG, UFRJ \\ rramos@mn.ufrj.br
}

Resumo: A Ilha do Catalão é uma das oito ilhas que foram unidas por aterro, a partir de 1951, para compor a Ilha do Fundão, onde está localizada a Cidade Universitária da UFRJ - Universidade Federal do Rio de Janeiro. Do antigo arquipélago, a Ilha do Catalão foi a única que teve mantida sua forma original, sendo ligada ao restante do campus por meio de um tômbolo artificial constituído por aterro, certamente produto da demolição de construções históricas, provavelmente do Centro da cidade. São reconhecidas na ilha ruínas de edificações do século XIX e XX, bem como depósitos de conchas atribuídos a acampamentos de antigos caçadores-coletores. Em sua porção norte foi identificada uma antiga lavra de rocha para cantaria e paralelepípedos. O objetivo deste trabalho é descrever a mineração e tecer considerações sobre o método de lavra utilizado. Para que isto fosse possível foi feita intensa pesquisa bibliográfica sobre a ilha; realizado o mapeamento geológico na escala 1:1.300; analisados detalhadamente os afloramentos e blocos com marcas de que foram lavrados; medidas as dimensões e espaçamento das marcas de inserção de cunhas e ponteiras para a extração dos blocos rochosos e utilizado o Programa em R, para tratamento estatístico dos dados, de forma a buscar correlações entre as medidas realizadas. Como resultados, sabese que, dentre os dois litotipos mapeados na ilha do Catalão, aquele explotado era o metagranitoide equigranular com enclaves deformados de biotita. Essa litologia possui foliação na direção regional NE-SW e mergulho médio de 30 para SSE, bem como dois padrões de faturamento: N60E e N26W. A maior atividade de extração localiza-se às margens da Baía de Guanabara, por onde o material lavrado era transportado por meio de barcaças ou chatas. Além de blocos brutos e paralelepípedos, foi identificada a ocorrência de um bloco com borda boleada (arredondada), indicando acabamento final realizado no local. Uma prospecção no terreno, com o uso de detectores de metais, levou à descoberta de sete ponteiras de ferro fundido para perfuração da rocha e outros objetos que podem ter ligação com os serviços necessários para a lavra. Foram medidos 334 orifícios em blocos e afloramentos, sendo que cada orifício possui em média 7-8 cm de profundidade (eixo maior), largura (eixo menor) média de $3-4 \mathrm{~cm}$ e média de abertura no topo de $2-3 \mathrm{~cm}$. 0 método de lavra utilizado consistia na perfuração manual de afloramentos e matacões da rocha, realizada com ponteiras metálicas. As perfurações eram feitas tanto perpendiculares quanto paralelas à foliação. As medidas não apresentaram grande dispersão de valores. Com a análise estatística foi possível interpretar que a variável espaçamento tem relação inversa com a profundidade, que, por sua vez, relaciona-se com todos os outros atributos. Finalmente, foi encontrada em uma revista de 1918 fotografia onde observa-se que, até aquele ano, os afloramentos ao longo da praia ainda não haviam sido lavrados. No entanto, nunca foram encontradas quaisquer menções à mineração na Ilha do Catalão, sugerindo que esta tenha sido clandestina e ocorrido entre as décadas de 1920 e 1940. A antiga lavra da Ilha do Catalão constitui, portanto, um patrimônio geomineiro extremamente relevante, sendo o único com estas características, grau de preservação e dimensões descrito na cidade do Rio de Janeiro.

Palavras Chave: antiga lavra, pedra-de-cantaria, Baía de Guanabara

Abstract: ILHA DO CATALÃO QUARRY: A FULL REGISTRATION OF A FORGOTTEN MINING IN GUANABARA BAY (RJ). The Island of Catalão is one of the eight islands that were connected by landfill, from 1951, to compose the Island of Fundão, where is located the University City of UFRJ - Federal University of Rio de Janeiro. From the old archipelago, the Catalão Island was the only one that had kept its original form, being connected to the rest of the campus by means of an artificial tombolo constituted by landfill, certainly product of the demolition of historical constructions, probably of the Center of the city. On the island are recognized ruins of 19th and 20th century buildings, as well as shell deposits attributed to former hunter-gatherer populations. In its northern portion was identified an old quarry for stonework and paving stones. The objective of this work is to describe the mining and to make considerations about the extraction method used. In order to make this possible, an intensive bibliographical research about the island was carried out; the geological mapping was done on the 1:1,300 scale; the outcrops and stone blocks with marks from which they were worked were analyzed in detail; measured the dimensions and spacing of the insertion marks of wedges and punches used to extract the blocks and applied the R program for statistical treatment of the data, in order to seek correlations between the measurements performed. As results, it is known that, among the two lithotypes mapped on the island of Catalão, the one exploited was the equigranular metagranitoid with deformed enclaves of biotite. This lithology has foliation in the NE-SW regional direction and 30 average dip for SSE, as well as two fracturing patterns: N60E e N26W. The largest extraction activity is located on the shores of Guanabara Bay, where the rock blocks were transported by barges or flatboats. In addition to raw blocks and paving stones, it was identified the occurrence of a block with rounded edge, indicating final finishing done in the place. A field survey with the use of metal detectors led to the discovery of seven cast iron punches for rock drilling and other objects that may be connected to the mining services. A total of 334 punch holes were measured in blocks and outcrops, each hole having an 7-8 $\mathrm{cm}$ average depth (major axis), 3-4 cm width (minor axis) and 2-3 cm average aperture at the top. The mining method used consisted of manual drilling of rock outcrops and boulders, carried out with iron punches. The perforations were made both perpendicular and parallel to the foliation. The measurements did not show great dispersion of values. With the statistical analysis, it was possible to interpret that the variable spacing has an inverse relationship with depth, which, in turn, is related to all other attributes. Finally, it was found in a 1918 magazine a picture where it is observed that until that year, the outcrops along the beach had not yet been worked. However, no mention was ever made of mining on the Island of Catalão, suggesting that it was clandestine and occurred between the 1920s and 1940s. The old mining of the Island of Catalão is therefore an extremely relevant mining heritage, unique with these characteristics, degree of preservation and dimensions described in the city of Rio de Janeiro.

Keywords: old quarry, stonework, Guanabara bay.

\section{INTRODUÇÃO}

A Ilha do Catalão está localizada na margem ocidental da Baía de Guanabara (Figura 1) e, desde o início dos anos 1950, faz parte da llha do Fundão, conectada a esta por um tômbolo artificial construído quando da implantação do aterro para a Cidade Universitária (Figura 2).

O aterro que formou a Cidade Universitária foi disposto entre os anos de 1949 e 1951. No tômbolo que liga a Ilha do Catalão ao restante da Cidade 
Universitária, são encontrados fragmentos de pedras-de-cantaria que certamente pertenceram a edificações, possivelmente do Centro da cidade (Figura 3), demolidas em uma de suas reformas urbanísticas.

Em visita à área em meados de 2013, foram identificadas marcas nos afloramentos rochosos e blocos que indicavam a existência de uma antiga mineração naquele local.
Segundo Almeida \& Porto Júnior (2002), o padrão geológico e geomorfológico da cidade do Rio de Janeiro, rodeada por grandes maciços rochosos que se sobrepõem a uma baixada alagadiça, fez com que a cidade, desde a sua origem, tivesse uma forte relação de dependência com as pedreiras, cujos produtos eram utilizados como material de construção, pavimentação e em ornamentos de fachadas.

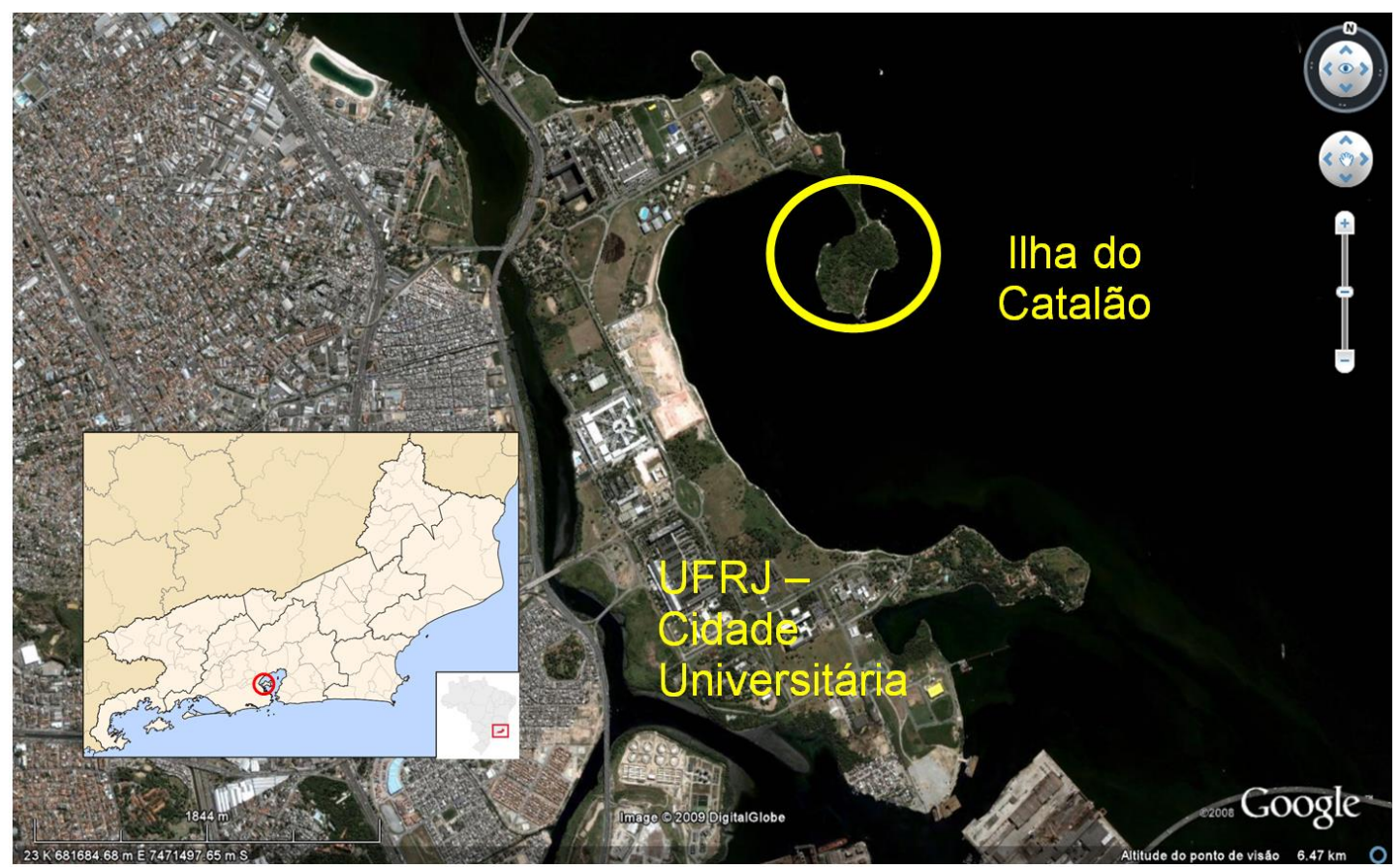

Figura 1. Mapa de localização da Cidade Universitária da UFRJ, com destaque para a Ilha do Catalão, na porção oeste da Baía de Guanabara.

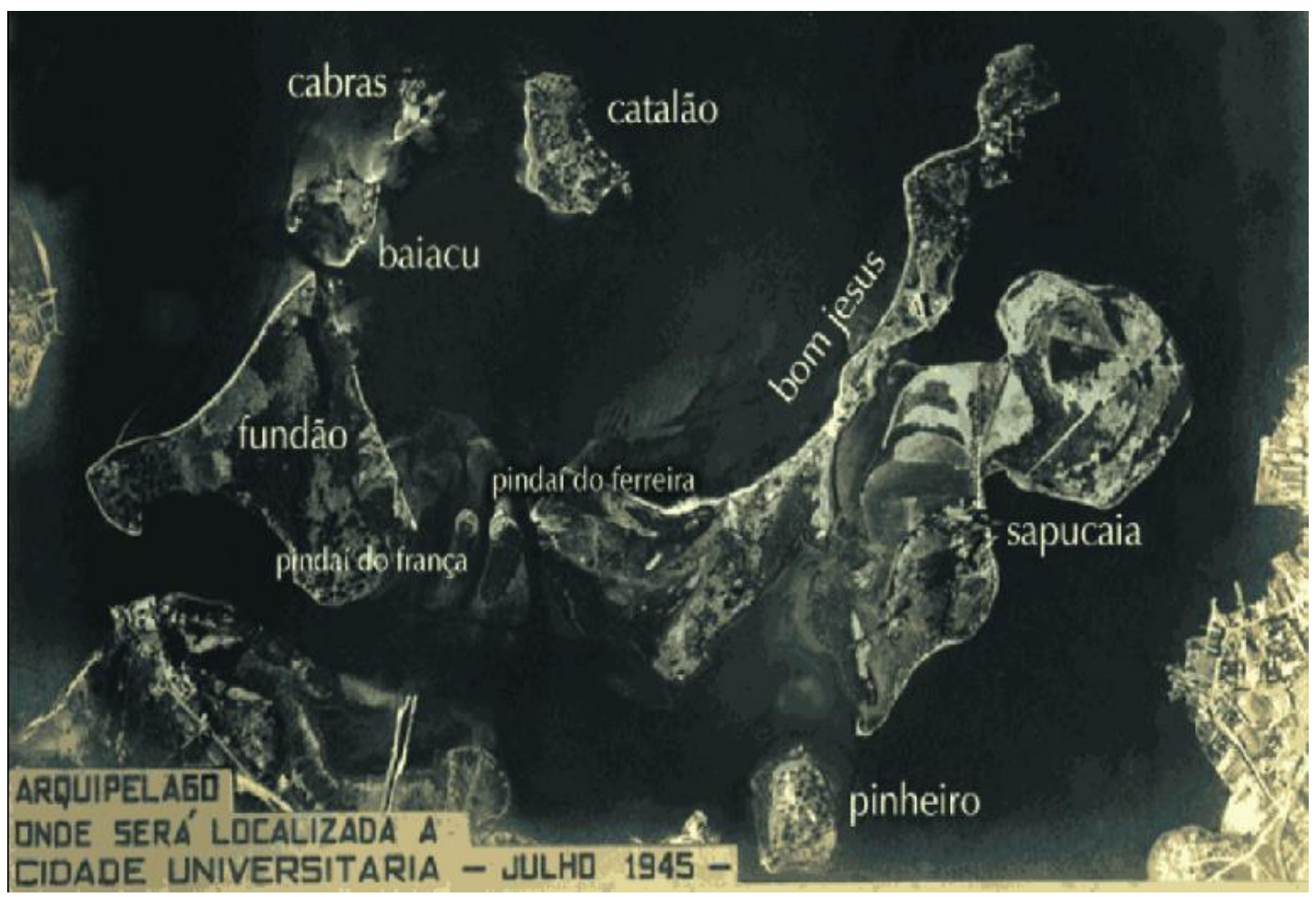

Figura 2. Arquipélago que foi unido por aterros para configurar a Cidade Universitária (Fonte: Acervo da UFRJ). 
A pedreira da llha do Catalão, situada nas coordenadas 2250'37,4"S e 4313'15,4”W (datum WGS84), constitui uma pequena lavra a céu aberto de pedra-de-cantaria e paralelepípedos, então situada nos arrabaldes da cidade. 0 método de lavra identificado é o da inserção de cunhas na rocha, de forma a separar os blocos nas dimensões desejadas (Figura 4).
O objetivo deste trabalho é apresentar os resultados dessa pesquisa (Ramos et al., 2014; Ramos et al., 2015; Vieira Filho et al., 2016), que mostra que a lavra do Catalão guarda todas as etapas do corte, desmonte, extração e beneficiamento da rocha.

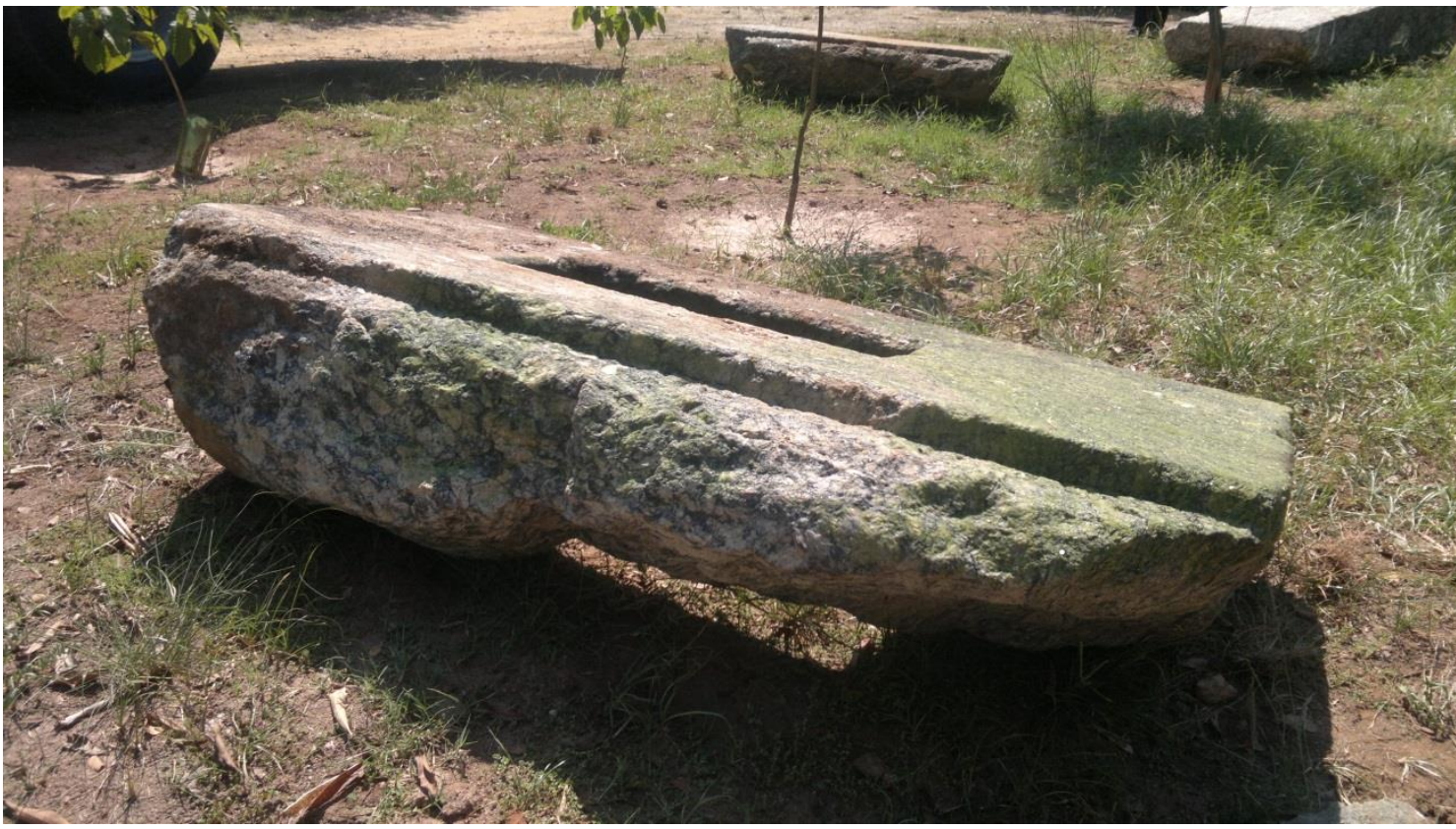

Figura 3. Pedra-de-cantaria em gnaisse facoidal encontrada no aterro do tômbolo que liga a Ilha do Catalão ao restante da Cidade Universitária.

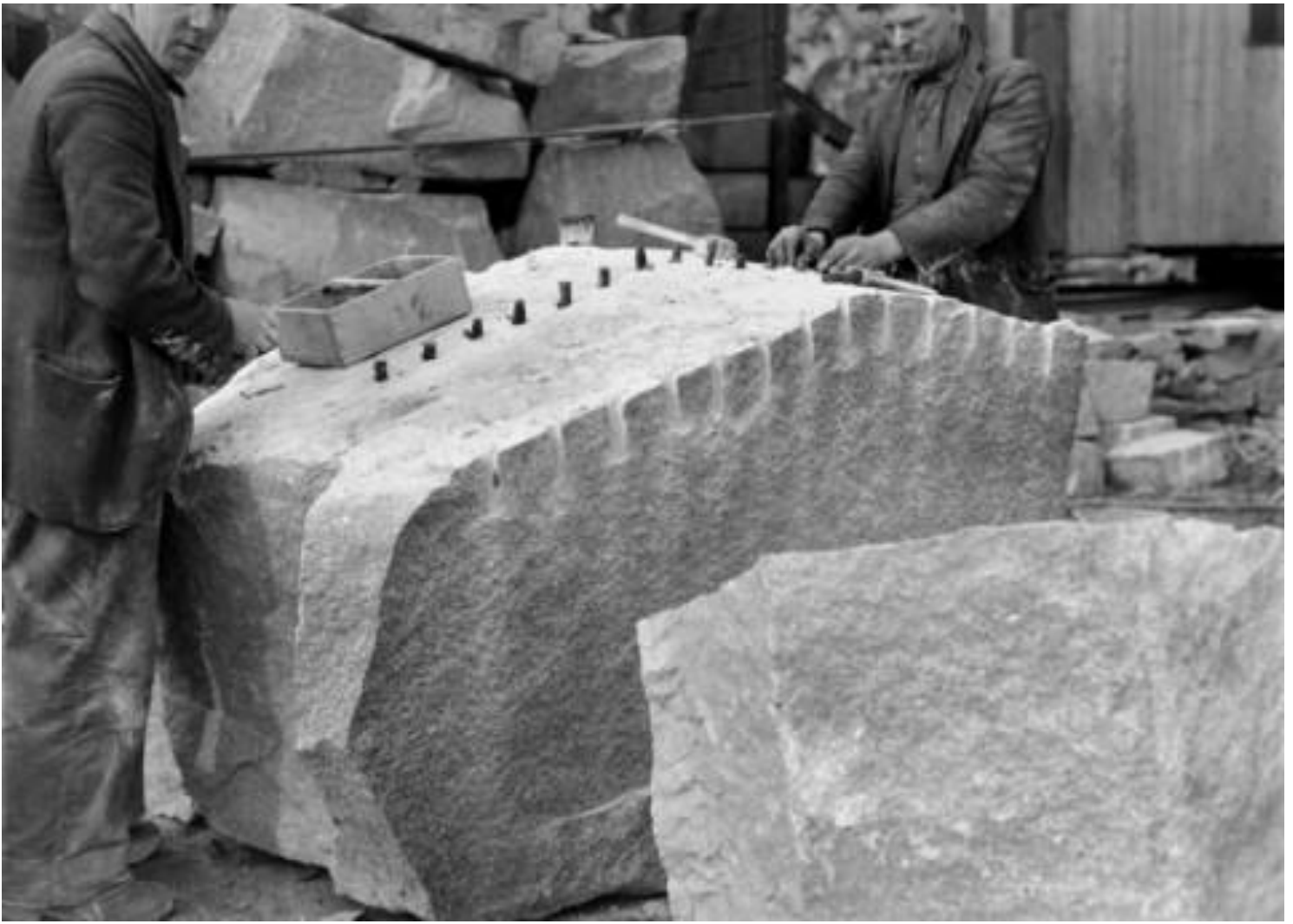

Figura 4. Método "Plug and feathers". Fonte: British Geological Survey, http://drystonegarden.com/index.php/2012/07/bgs-quarry-photos/ 


\section{MATERIAL E MÉTODOS}

Inicialmente, foi realizado levantamento detalhado da área, que foi subdividida em setores, de modo a identificar a extensão da lavra. Cada setor foi, então, estudado separadamente, sendo medidas, com auxílio de régua e trena, as dimensões dos orifícios de inserção das ponteiras de ferro (punch holes), utilizadas na técnica de separação dos blocos, bem como o espaçamento entre estes.

Estes dados foram, então, submetidos a um estudo estatístico utilizando o Programa em $R$ (Braga, 2015), para indicar possíveis correlações entre os parâmetros medidos, com o intuito de identificar se os mineradores seguiam algum padrão na disposição dos punch holes no que se refere ao espaçamento e aprofundamento dos mesmos, bem como a disposição destes em relação ao plano de foliação da rocha.

Para a análise multivariada foram utilizados os parâmetros coletados e medidos em campo, que são Largura 1, Largura 2, Profundidade e Espaçamento (Figura 5). Foram utilizados os pacotes stats e cluster da plataforma $R$ para calcular os parâmetros estatísticos de distribuição das medidas. Primeiramente foram gerados gráficos de distribuição de frequências (histogramas) relativos aos parâmetros medidos, permitindo uma visão geral do conjunto de dados.

Ainda, com o intuito de correlacionar as variáveis medidas (Espaçamento, Profundidade, Largura 1, Largura 2) foi realizada uma Análise de Componentes
Principais (ACP), onde cada componente principal é uma combinação linear de todas as variáveis. Este procedimento visa explicar a maior parte da variância, analisando assim a inter-relação entre as variáveis e a distribuição dos parâmetros (pontos no bi-plot) com respeito a estas. Para agregar mais dados quantitativos, foi gerado um dispersograma entre variáveis que apresentaram uma boa relação estatística, bem como efetuada uma análise de agrupamento (clusters), com objetivo de agrupar objetos buscando a similaridade entre eles (Landim,1998).

Foi realizado mapeamento geológico para identificar as litologias e principais estruturas tectônicas, bem como a distribuição da lavra em relação ao arcabouço geológico-estrutural da Ilha do Catalão. O trabalho se iniciou no pré-campo, com a integração em GIS de um mosaico formado por imagens de satélite de alta resolução espacial (obtidas na página eletrônica do Instituto Pereira Passos) da folha Ilha do Governador - NO 1:25.000, elaborada pela Diretoria do Serviço Geográfico do Exército Brasileiro.

O mapeamento geológico-estrutural de detalhe foi realizado na escala 1:1300, cobrindo uma área de cerca de $136.000 \mathrm{~m}^{2}$, tendo como base cartográfica o mosaico de imagens de satélite georreferenciadas em datum WGS-84. Foram realizadas três campanhas de campo cada uma com duração de um dia, sempre em condições de maré baixa, para uma melhor visualização dos afloramentos situados na orla da ilha. Além disto, foram preparadas lâminas delgadas dos principais litotipos.

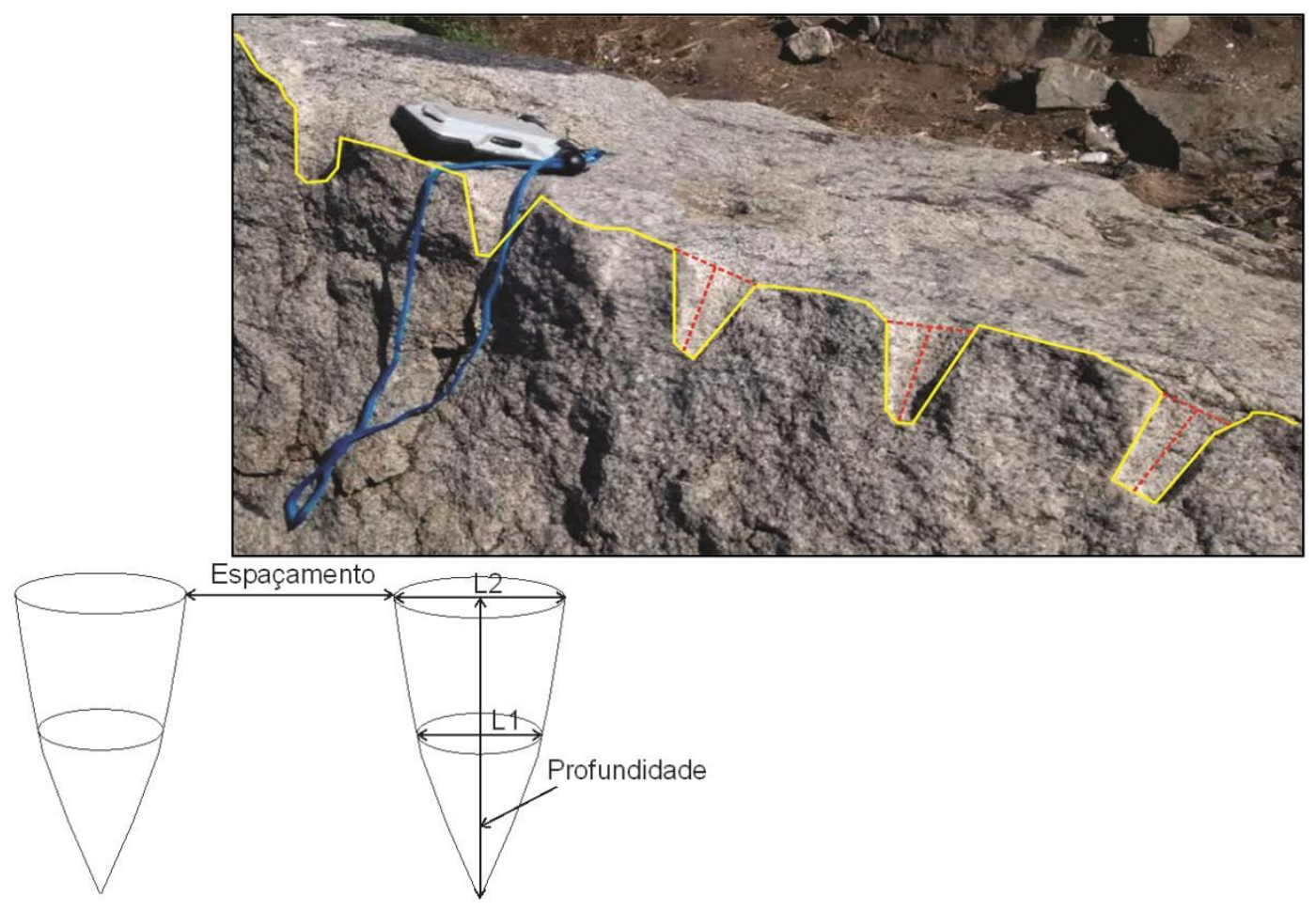

Figura 5. Esquema com a indicação das variáveis medidas: Espaçamento, Largura 1, Largura 2 e Profundidade. 
Também foi realizado um levantamento preliminar com detectores de metais para buscar ferramentas ou materiais que pudessem contribuir com a contextualização da lavra ou sobre a época de seu desenvolvimento. Com este mesmo objetivo, foi realizada pesquisa detalhada em arquivos de revistas e jornais.

\section{RESULTADOS}

\subsection{Levantamento na área da mineração}

A perfuração manual de afloramentos e matacões era realizada através de uma sequência linear de orifícios espaçados (punch holes), realizados com ponteiras metálicas. Foram medidos, com auxílio de trena e régua, 334 orifícios em 54 blocos / afloramentos.

Através do mapeamento da área e do registro detalhado do processo minerário, observou-se que a primeira etapa era o talhe de um "risco" na superfície da rocha pelo "mestre canteiro" ou operário mais experiente, objetivando orientar a abertura de uma linha de orifícios. Cada orifício possui em média $7-8 \mathrm{~cm}$ de profundidade (eixo maior); largura (eixo menor) média de $3-4 \mathrm{~cm}$; e média de abertura no topo de $2-3 \mathrm{~cm}$. As perfurações eram feitas tanto perpendiculares quanto paralelas à foliação. Nos orifícios eram colocadas ponteiras de ferro e, através da percussão simultânea com marretas em diferentes orifícios, o bloco rochoso era separado do maciço (figuras 4 e $6)$.

A área da lavra que demonstrou ter havido uma maior atividade extrativa foi aquela próxima à Baía de Guanabara (Figura 7), por onde eram transportados os blocos através de barcaças ou chatas. Uma descoberta notável foi a ocorrência de um bloco lavrado, com borda boleada, abandonado na margem da baía (Figura 8).

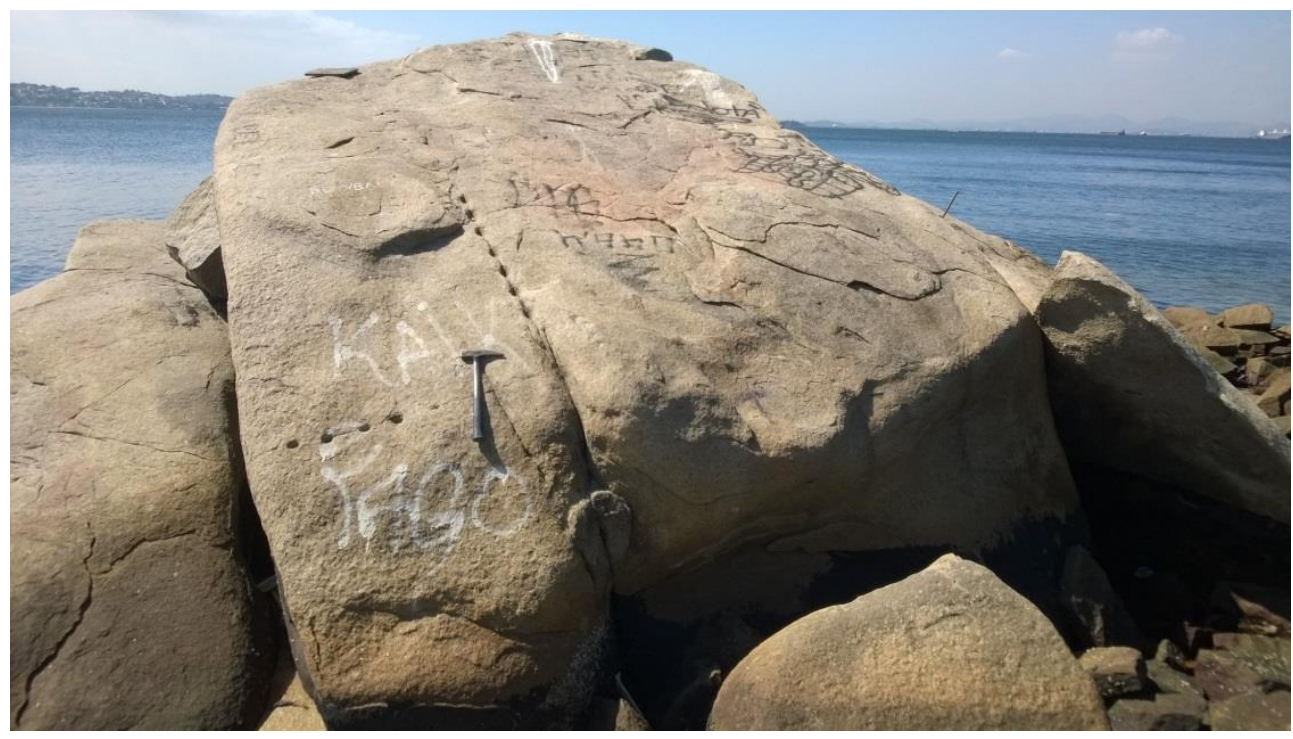

Figura 6. Marcação da linha de orifícios e o início de sua perfuração. Observar os alinhamentos em direções ortogonais.

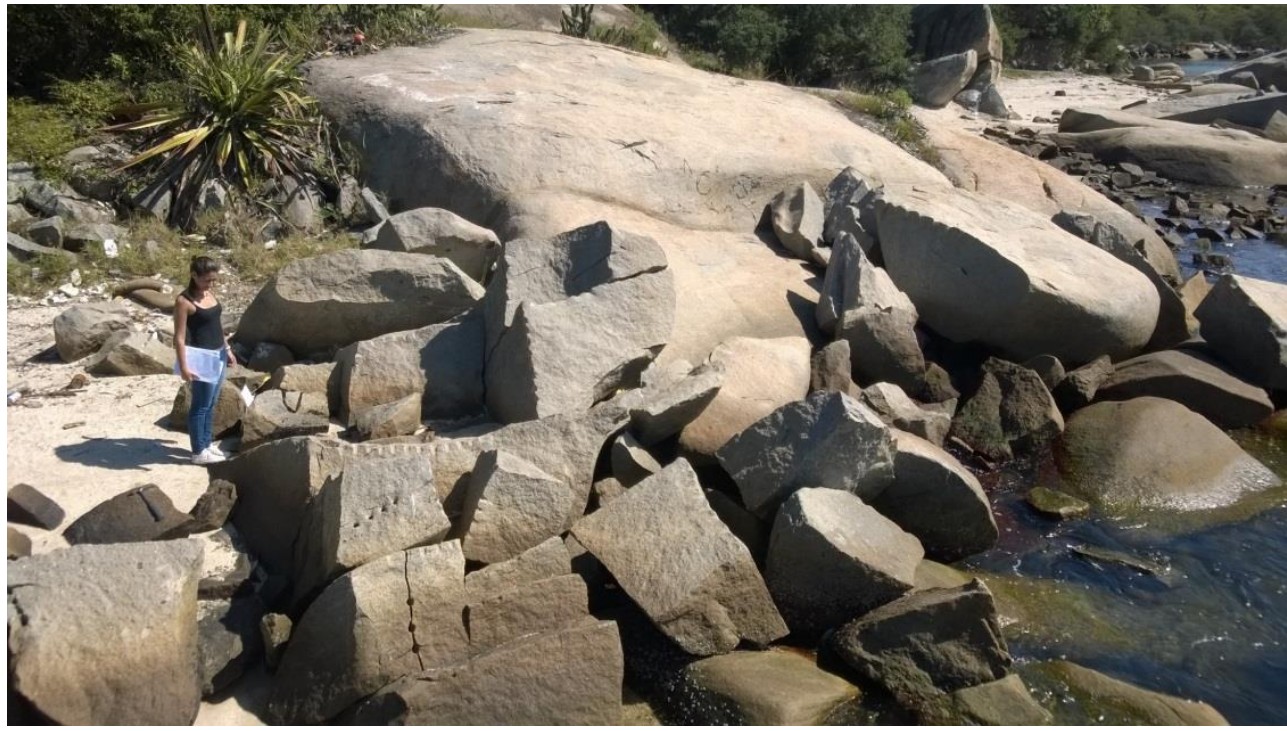

Figura 7. Área com grande concentração de evidências de lavra na margem da baía de Guanabara. 


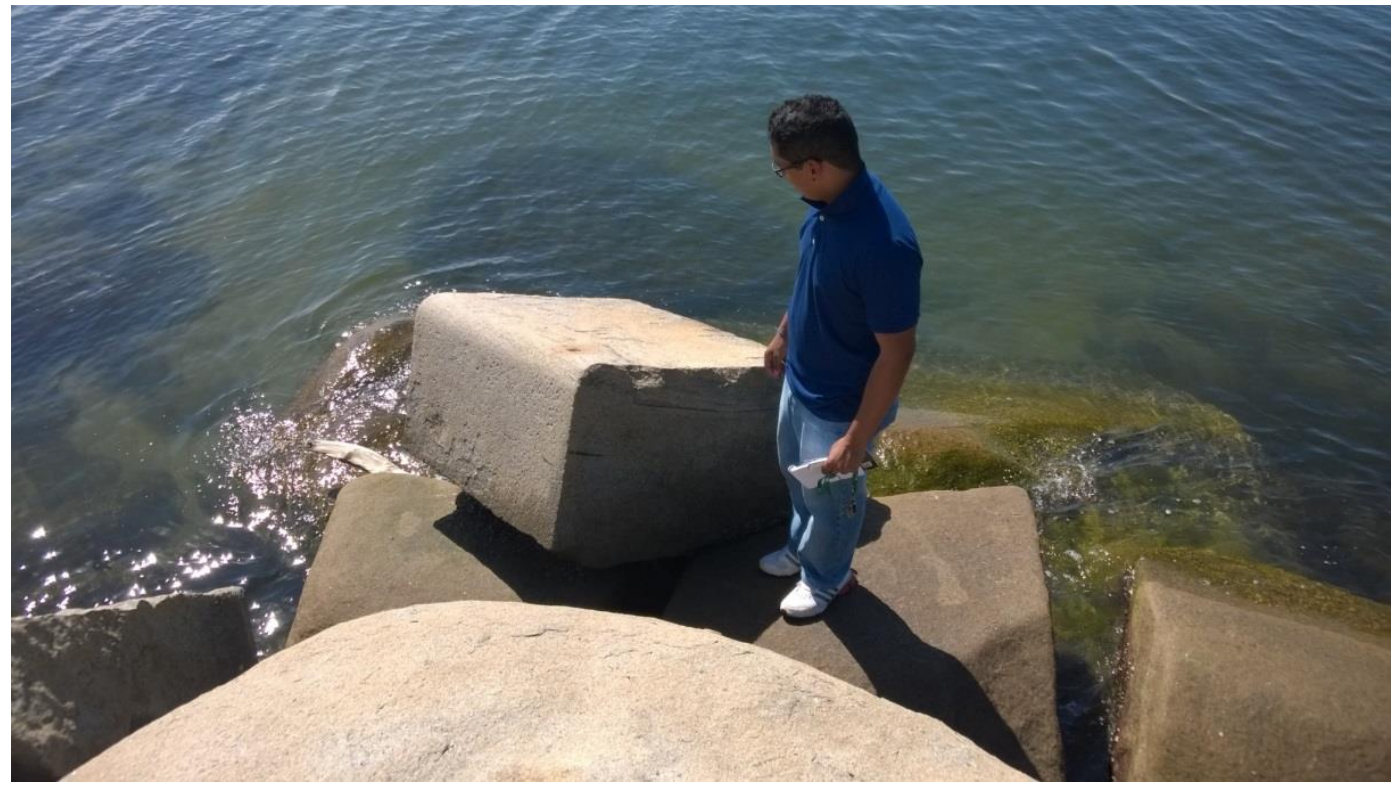

Figura 8. Bloco com borda arredondada (boleada) às margens da Baía de Guanabara.

Posteriormente, foi encontrada uma ponteira metálica encravada em um dos orifícios e, através de prospecção do terreno com o uso de detectores de metais, foram descobertas sete destas ponteiras (Figura 9) e outros objetos que podem ter ligação com os serviços necessários para a lavra. Entre estes, destaca-se um fragmento de cerâmica com a marca da Fábrica Santo Eugênio, que funcionou com este nome entre os anos de 1920 e 1940, cuja história pode ser consultada em http://www.angelfire.com/ ab8/santoeugenio/index_pri_1.html e http://www. porcelanabrasil. com.br/historia22.htm.

Durante a pesquisa, foram identificados vestígios de lavra tanto para pedra-de-cantaria como para paralelepípedos (figuras 10 e 11).

Durante a pesquisa bibliográfica sobre a Ilha do Catalão, foi encontrada em um exemplar da revista "Eu sei tudo" (CEA, 1918) uma fotografia com a llha do Catalão ao fundo (Figura 11), exatamente no trecho onde se localiza a lavra. Identificado, através do Google Earth, o local de onde foi obtida a antiga imagem (afloramento situado $57 \mathrm{~m}$ a NNE da extremidade norte da ilha), foi contratado um barco e fotografada a orla da ilha do mesmo local onde o jornalista o havia feito há quase um século (Figura 12). Comparando-se as imagens, constatou-se que a lavra ainda não havia sido iniciada em 1918.

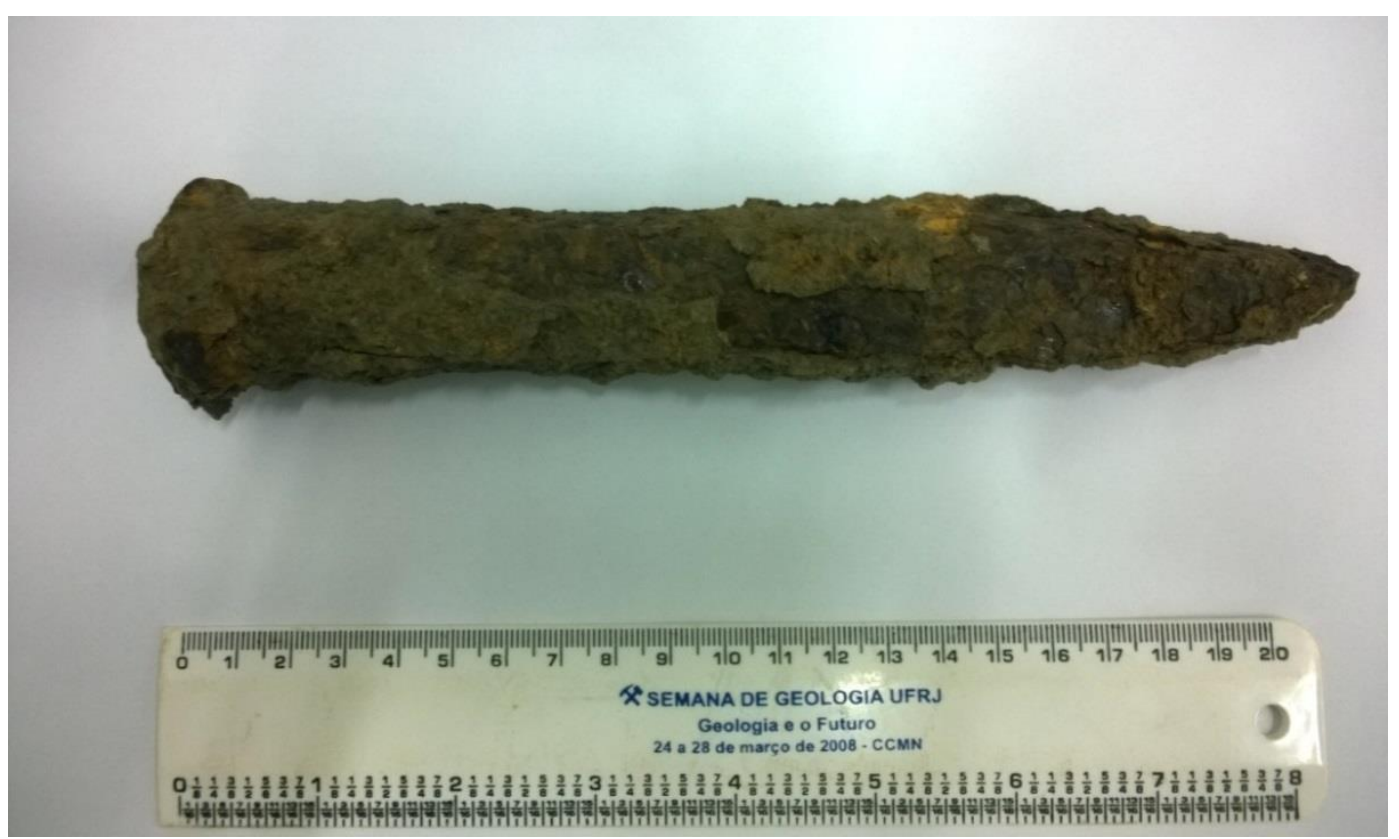

Figura 9. Ponteira de ferro fundido encontrada na área da antiga lavra. 


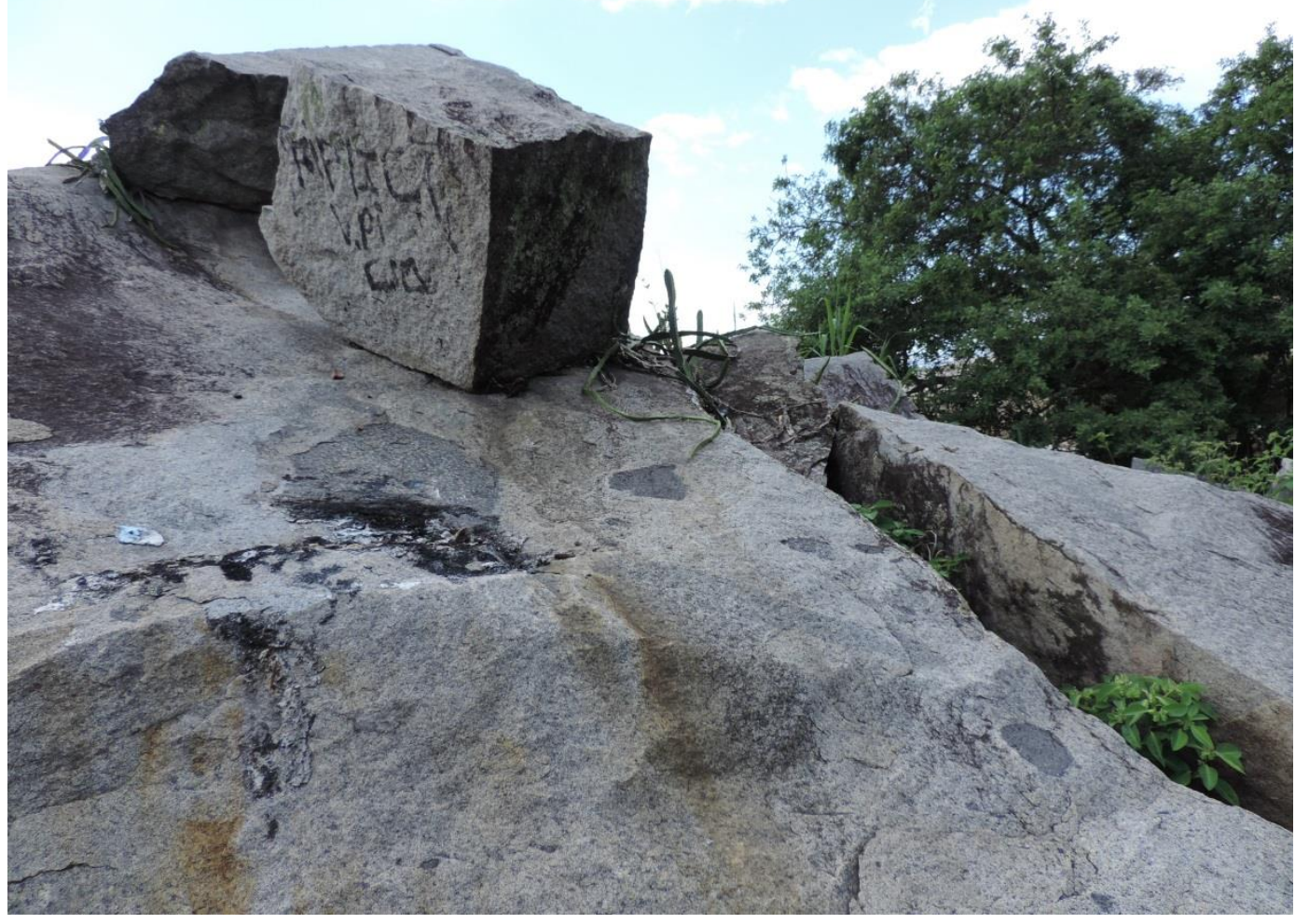

Figura 10. Bloco lavrado, já separado do maciço rochoso. Notar os enclaves biotíticos (manchas acinzentadas) no metagranitóide equigranular.

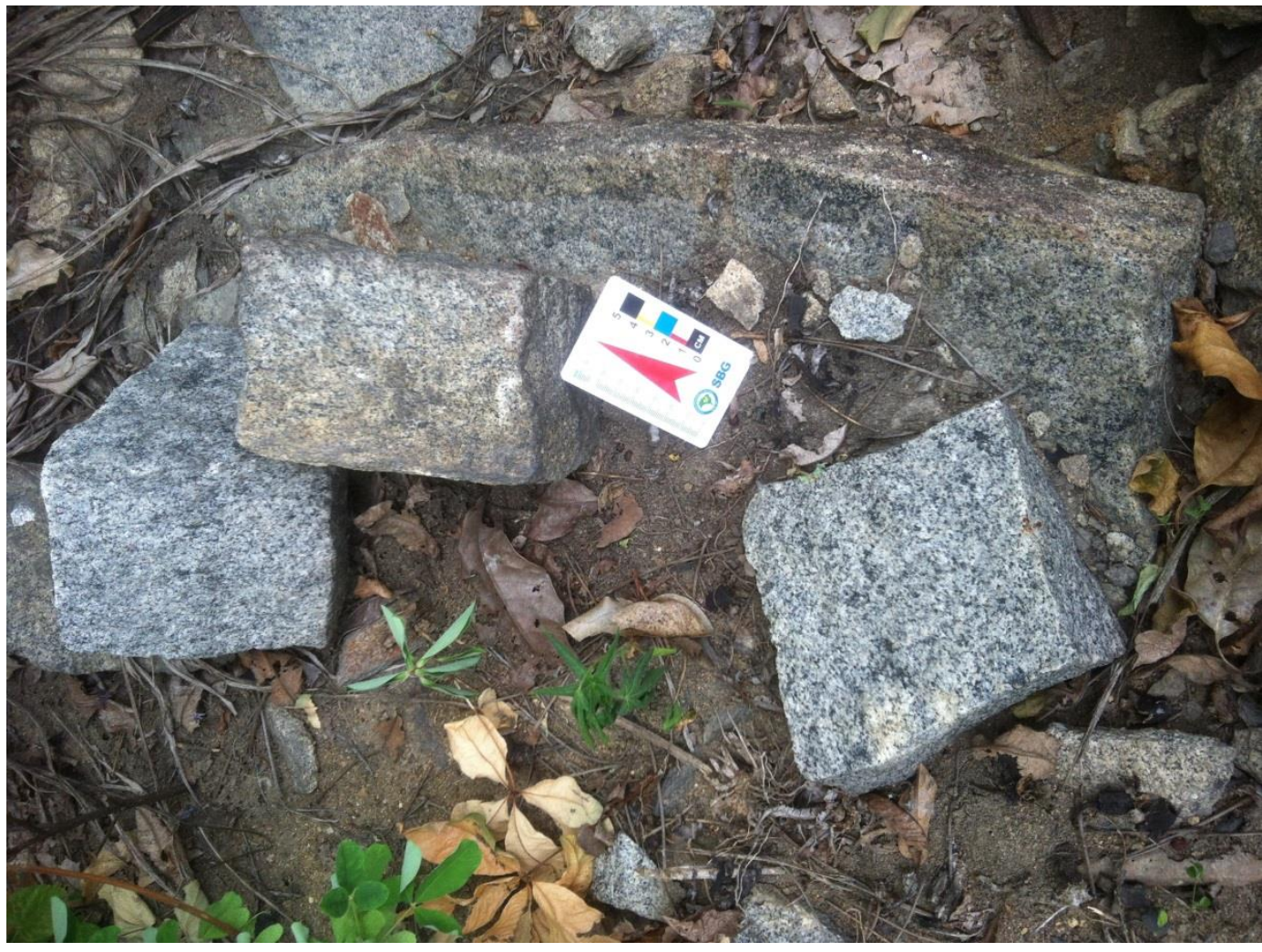

Figura 11 - Paralelepípedos grosseiramente talhados deixados na área de lavra. 


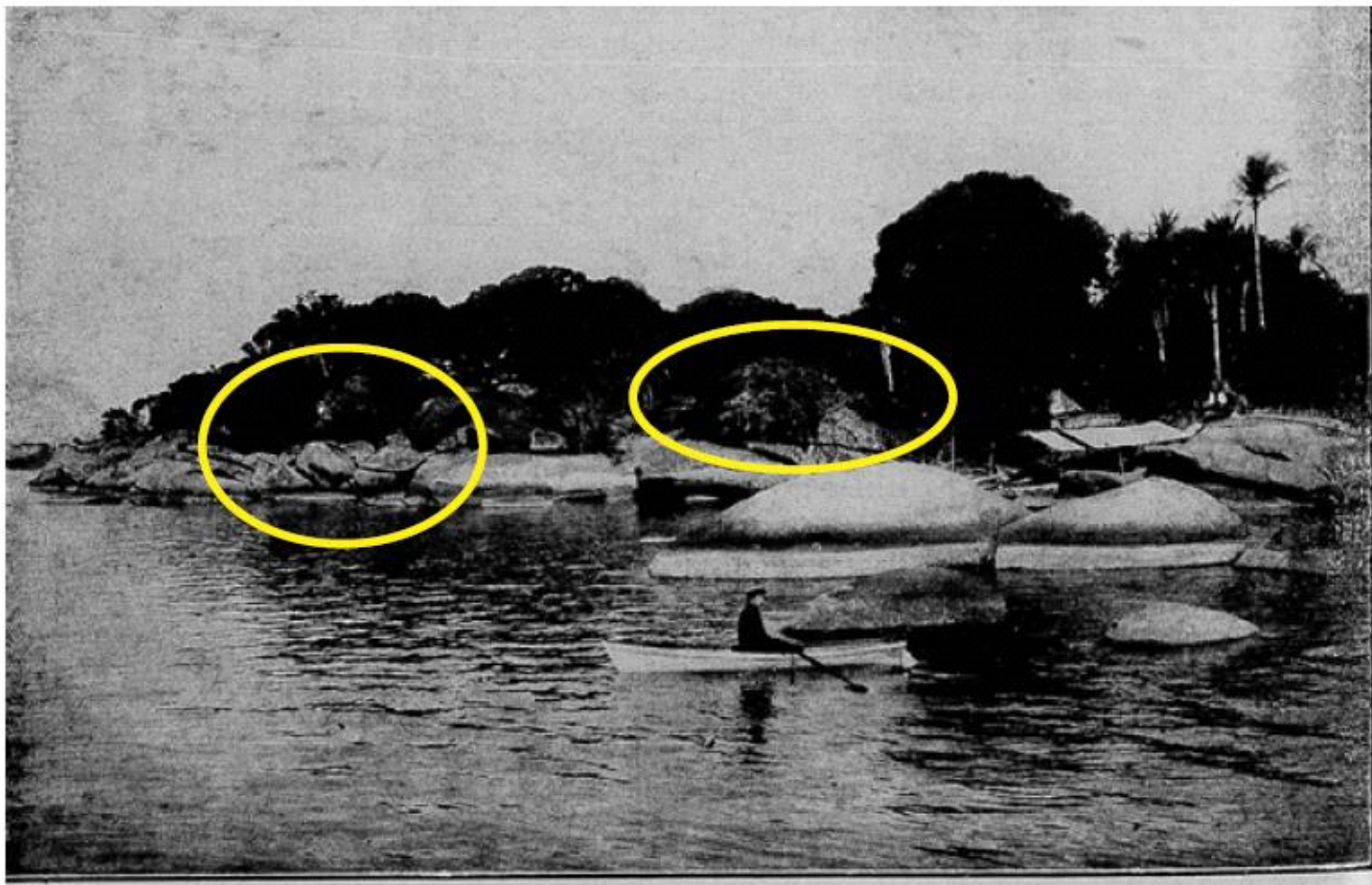

Figura 12. Imagem da llha do Catalão em 1918 (CEA, 1918).

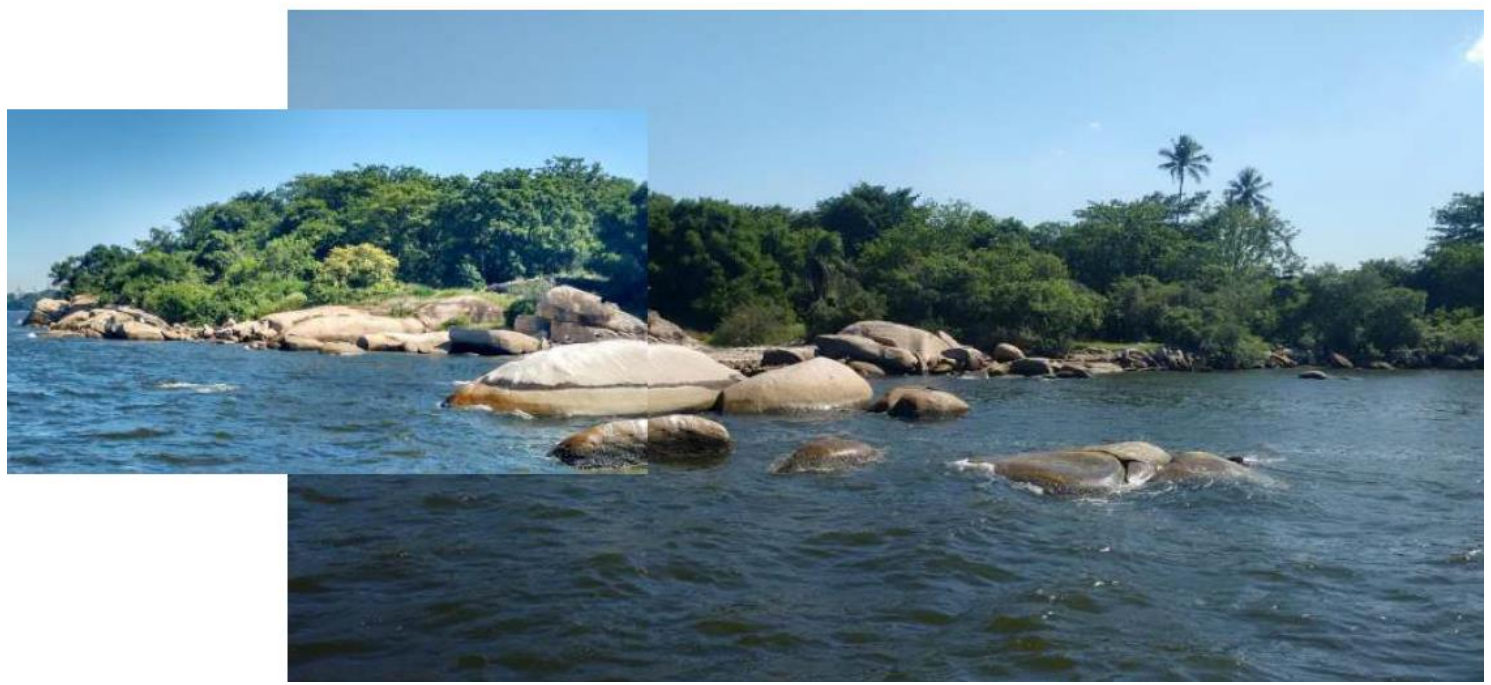

Figura 13. Imagem da Ilha do Catalão em 2015. Observe que na Figura 10 existem blocos que hoje não mais são encontrados na praia.

Considerando este fato e que as cerâmicas lá encontradas são contemporâneas à lavra, acreditase que esta deva ter se desenvolvido entre as décadas de 1920 e 1940. Vale ressaltar que o aterro para a construção da Cidade Universitária foi iniciado em 1949.

\subsection{MAPEAMENTO GEOLÓGICO NA ESCALA 1:1.300}

Durante as campanhas de campo foram registradas duas unidades de mapeamento separadas essencialmente pela textura. A primeira consiste de um metagranitoide equigranular (Figura 14) localmente bandado, com enclaves de biotitito marcando a foliação e xenólitos com até $4 \mathrm{~m}$ de diâmetro de um gnaisse escuro com forte bandamento milimétrico. A segunda, um metagranitoide porfirítico (Figura 15), possui fenocristais bem formados de K-feldspato com até 2 $\mathrm{cm}$ de diâmetro. Ambas as unidades são cortadas por diques retilíneos de pegmatito de até $50 \mathrm{~cm}$ de espessura com espessuras e orientações diversas.

A foliação principal possui atitude média 50/30 e é dada pela orientação de minerais micáceos presentes nos metagranitóides. Infere-se que o contado litológico entre as duas unidades mapeadas acompanhe essa atitude e se encontre na região central da Ilha do Catalão (Figura 16). 


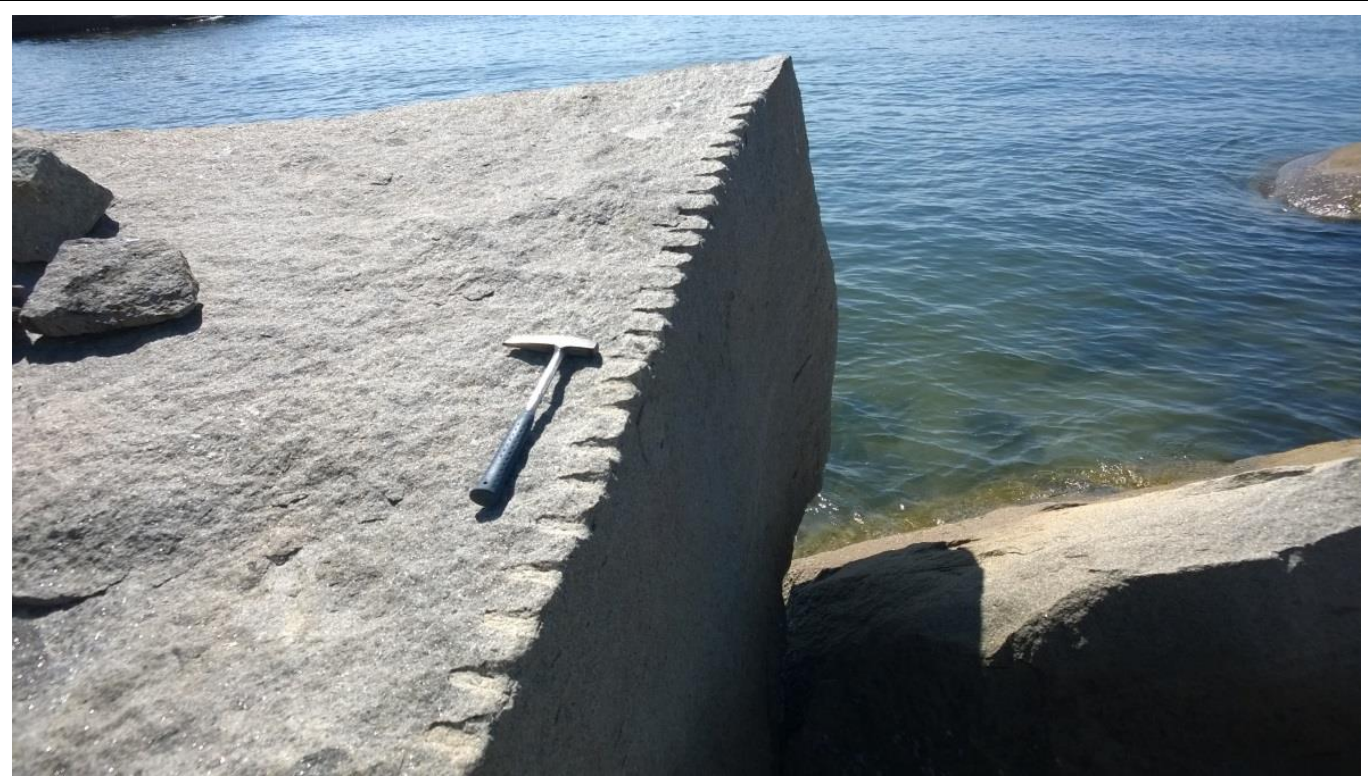

Figura 14. Metagranitóide equigranular com as marcas da lavra paralelas à foliação da rocha.

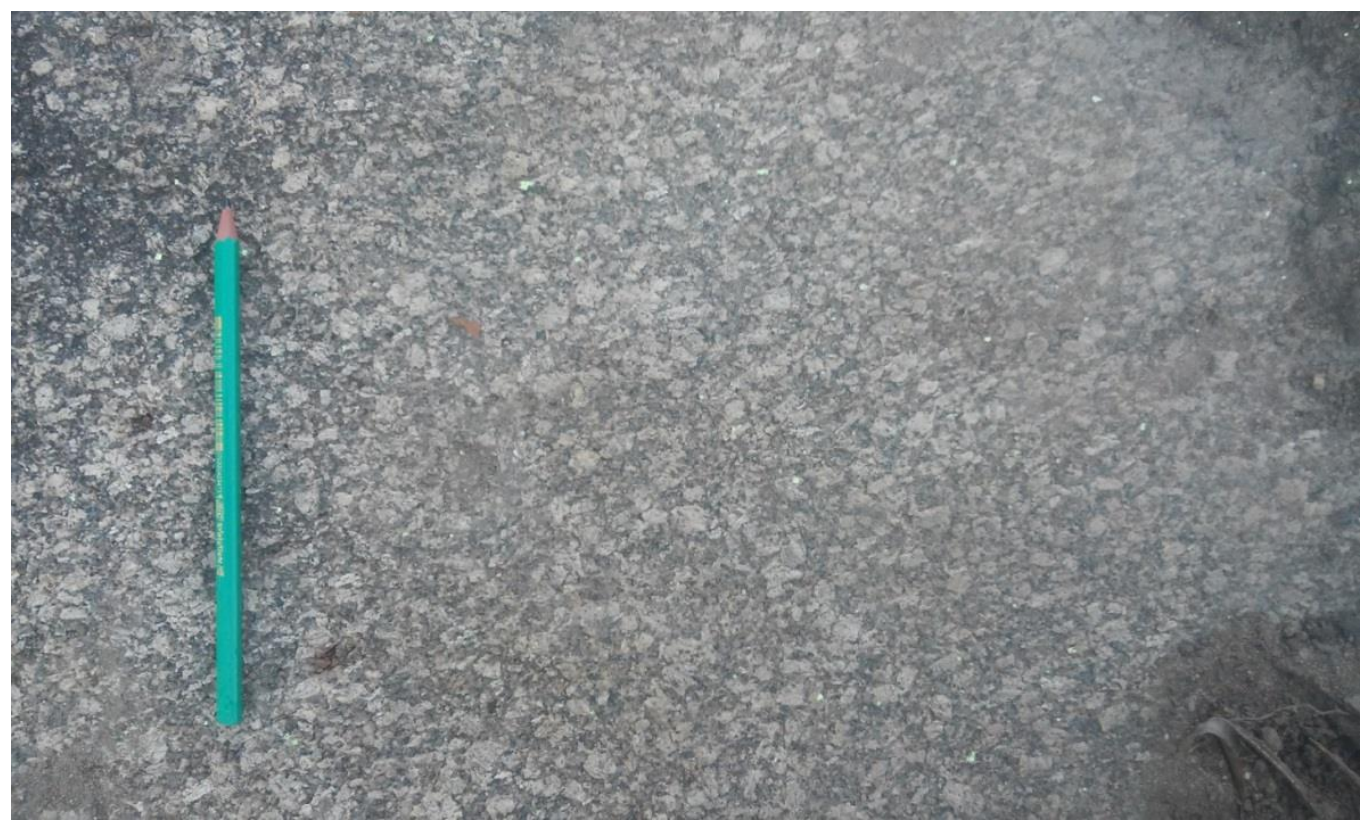

Figura 15. Aspecto da textura do metagranitóide porfirítico.

A área possui duas famílias de fraturas ortogonais entre si, que são de muito fácil percepção em imagem de satélite, com orientações NE-SW e NW-SE.Foi realizada análise de lâminas delgadas em microscópio petrográfico de cada um dos litotipos. $\mathrm{O}$ metagranitóide equigranular possui mineralogia formada basicamente por quartzo, microclina, plagioclásio e biotita, sendo que o metagranitóide porfirítico possui mineralogia semelhante, com menores percentuais de biotita e maiores de allanita. As composições mineralógicas, quando plotadas no gráfico de Streckeisen, indicaram uma composição no campo dos alcali-feldspato granitos para ambos os litotipos.

\subsection{Análise Estatística Multivariada}

Os histogramas de densidade (Figura 17), associados com a curva normal correspondente, apresentaram uma feição assimétrica à direita, com valores elevados em relação à mediana das amostras.

A Análise de Componentes Principais (Figura 18) permitiu interpretar que Profundidade e Espaçamento são os atributos mais significativos, porque os vetores que expressam essas variáveis são os de maior dimensão. Mostra ainda que Profundidade, Largura 1 e Largura 2 estão fortemente associados, porque os vetores que expressam essas variáveis estão praticamente na mesma direção do vetor que expressa a profundidade. 
R.R.C. Ramos et al. / Geonomos, 24(2), 140-152, 2016 www.igc.ufmg.br/geonomos

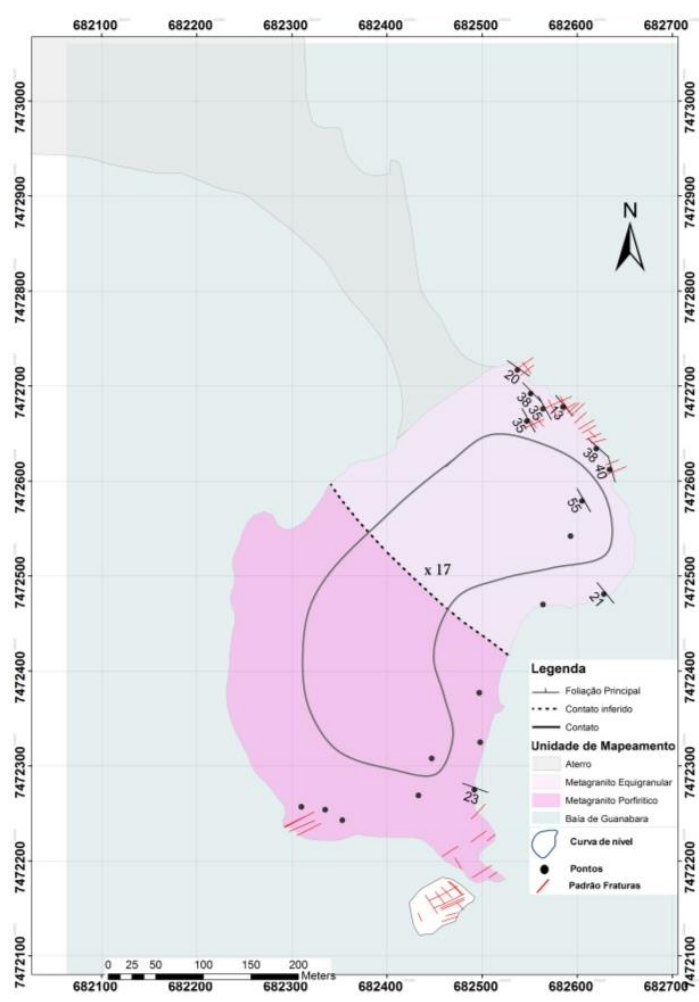

Figura 16. Mapa Geológico da Ilha do Catalão.
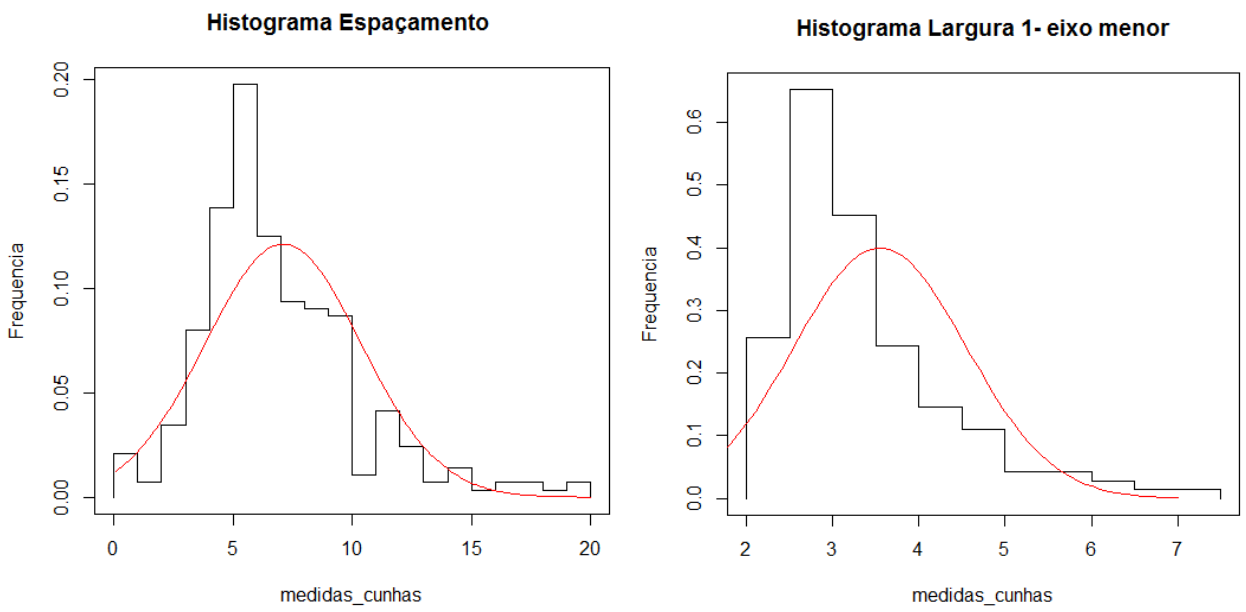

Histograma Largura 2- Abertura Topo

Histograma Comprimento - eixo maior profundidade
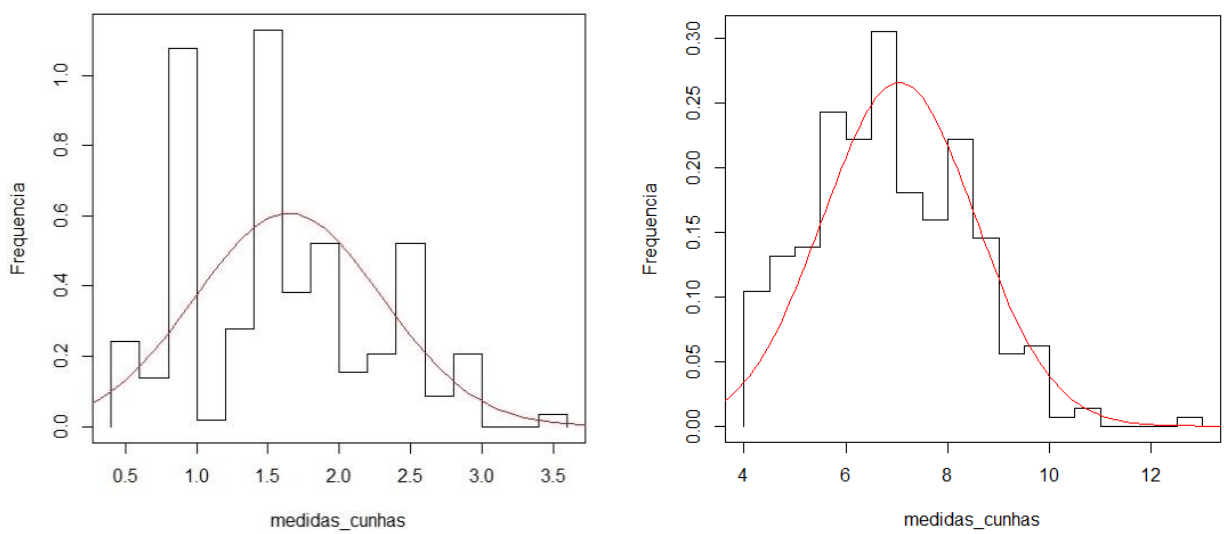

Figura 17. Histogramas de densidade para as variáveis medidas 


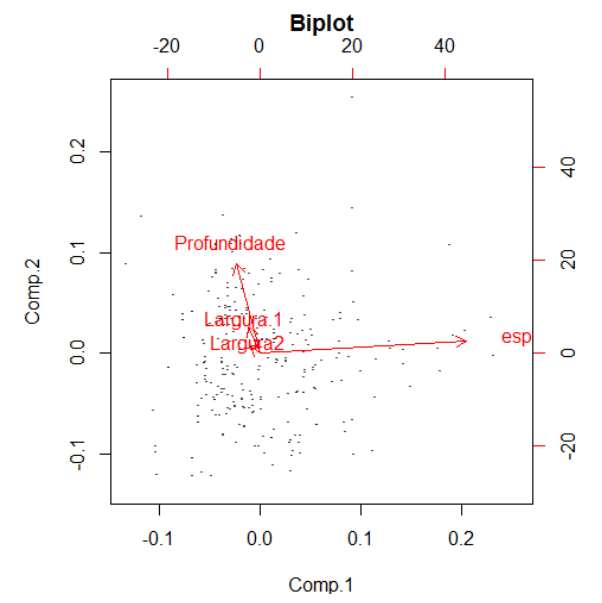

Figura 18. Gráfico demonstrativo da Análise de Componentes Principais (PCA).

\section{Largura 1 x largura 2}

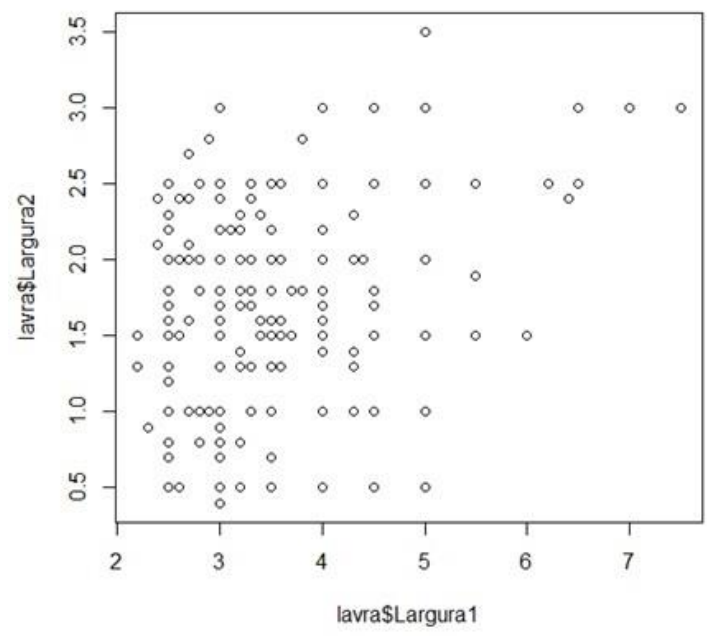

Profundidade $\mathrm{x}$ largura 2

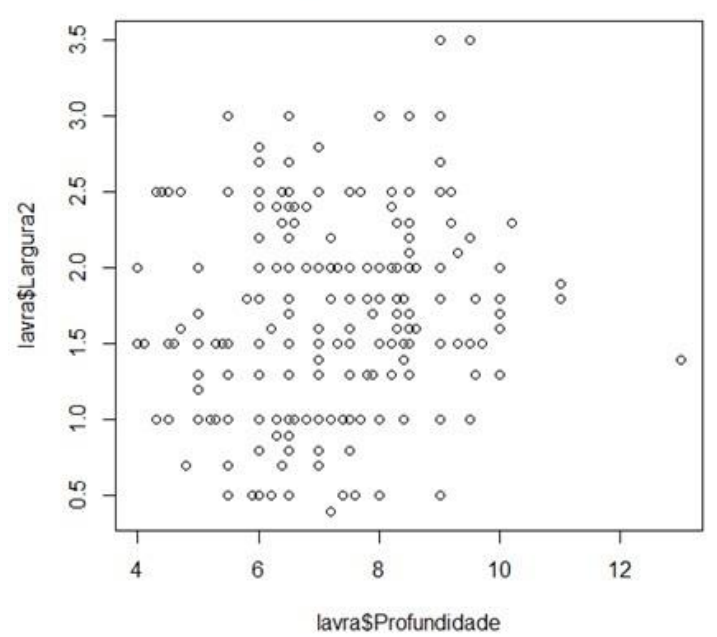

O conjunto de gráficos que configura o dispersograma (Figura 19) analisa a proximidade ou separação entre os pares de pontos relativos às variáveis. O resultado obtido reafirma a informação obtida com o PCA que apontou para uma forte relação linear entre Profundidade, Largura 1 e Largura 2.

A Análise de Agrupamento (Cluster Analysis) revelou que o atributo profundidade é o que melhor discrimina os grupos de blocos mapeados (cores) (Figura 20). Para as outras variáveis os grupos se interpenetram.
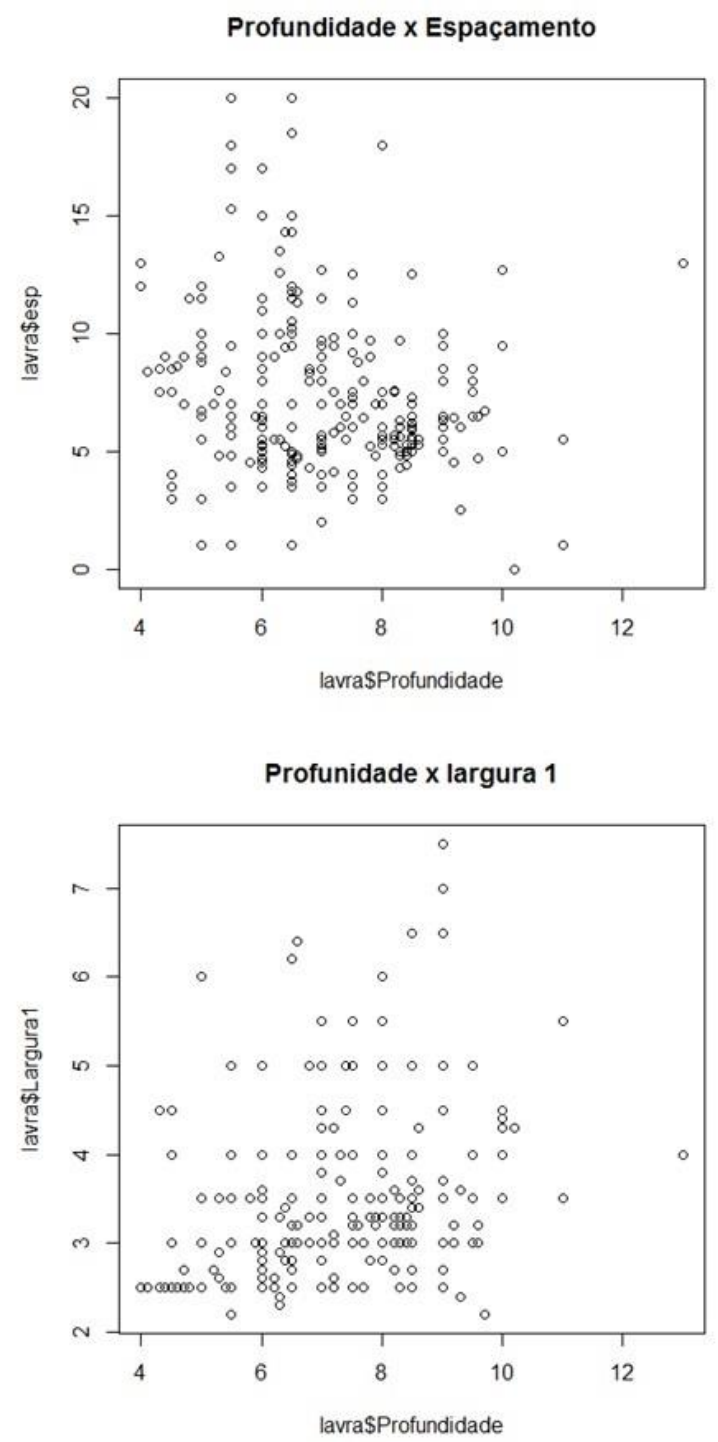

Figura 19. Dispersograma indica a relação entre as variáveis 


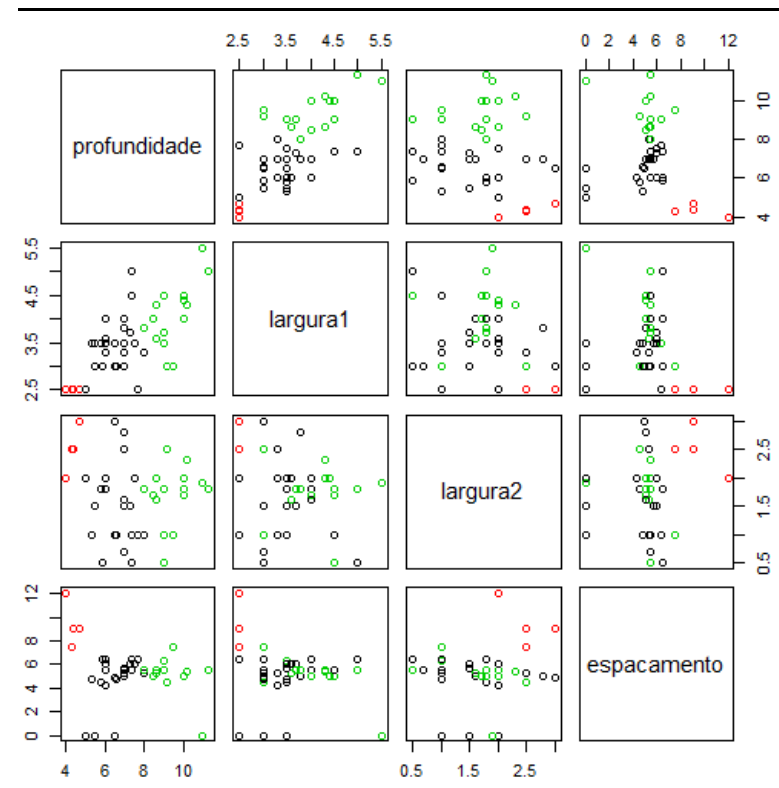

Figura 20. Análise de clusters, mostrando a relação entre as variáveis.

\section{CONCLUSÕES}

\subsection{Mapeamento Geológico}

O mapeamento geológico demonstrou que o metagranitoide equigranular foi o litotipo explotado na mineração do Catalão. Ficou muito claro que a extração não ultrapassou a contato desta litologia com o metagranitoide porfirítico.

O metagranitoide equigranular apresenta forte foliação NE-SW com mergulhos entre 20 e 55 para SW, sendo este plano de fraqueza o aspecto que condicionou a extração da pedra para cantaria.

O padrão de fraturas também teve papel importante no método de extração, pois os dois planos encontrados nos blocos lavrados eram perpendiculares entre si, sendo assim um facilitador para a remoção dos blocos de interesse na extração.

\subsection{Análise Estatística}

Com a análise estatística foi possível interpretar que a variável Espaçamento tem relação inversa com a Profundidade, que, por sua vez, relaciona-se com todos os outros atributos, sendo assim uma importante informação quanto a percepção da metodologia de extração realizada pelos antigos mineiros.

Pode-se concluir que as variáveis Profundidade e Largura1 são fortemente associadas e, em menor intensidade, também a Largura 2. Já a variável Espaçamento varia pouco em relação às demais variáveis, demonstrando pouca associação com elas. Assim os agrupamentos são definidos prioritariamente pelas variáveis Profundidade, Largura 1 e Largura 2.

\subsection{Idade e operação da lavra}

O método de lavra descrito na pedreira da llha do Catalão é utilizado desde a antiguidade até os dias atuais, não sendo, portanto, um indício de uma idade da lavra estudada. Inicialmente aventou-se a hipótese da lavra ter ocorrido ainda no século XIX, entretanto, a análise comparativa realizada com a fotografia obtida em 1918 mostrou que esta é posterior a esse ano, sendo aqui sugerido um período de operação entre os anos 1920 e 1940.

O registro na lavra de blocos em diferentes estágios do processo de extração, sendo alguns aparentemente abandonados logo após serem separados do maciço rochoso, sugere que a lavra tenha tido operação intermitente ou, mesmo, que tenha sido interrompida bruscamente. A ocorrência de um bloco beneficiado na margem da baía de Guanabara, lá disposto para ser embarcado, reforça a hipótese da lavra ter sido abandonada repentinamente.

Até o momento não foram encontrados registros históricos sobre esta mineração. Acredita-se, portanto, que tenha sido uma lavra clandestina.

Pretende-se, ainda, apoiar a realização de um estudo de arqueologia industrial na área da lavra, com o intuito de encontrar outras ferramentas e objetos a ela relacionados, bem como estudar as ponteiras metálicas encontradas, para melhor caracterização do período de operação da mineração e as técnicas e tecnologia da sua época.

A antiga lavra da Ilha do Catalão guarda todas as etapas do processo de extração e beneficiamento de pedras-de-cantaria, constituindo um patrimônio geomineiro extremamente relevante, sendo o único com estas características, grau de preservação e dimensões descrito na cidade do Rio de Janeiro.

\section{REFERÊNCIAS BIBLIOGRÁFICAS}

ALMEIDA, S.; PORTO JÚNIOR, R. Cantarias e pedreiras históricas do Rio de Janeiro: instrumentos potenciais de divulgação das Ciências Geológicas. Terrae Didatica, Vol. $8, N^{\circ} 1,2002$, págs. 3-23.

BRAGA, L. Introdução à Geoestatística: com programas em R. Ed. E-papers. 2015, 132p.

LANDIM, B. Análise de Dados Geológicos. Ed. Unesp, 1998, 226p.

RAMOS, R. R. C.; MANSUR, K. L.; IAFFE, A.; VIEIRA FILHO, C. L. A.; MOZART, M.S.; CARVALHO, M. D. S. Lavra de pedra-decantaria da Ilha do Catalão: notável patrimônio geomineiro carioca. In: Simpósio Brasileiro de Patrimônio Geológico, 3. Lençóis. Anais...Lençóis: Universidade Estadual de Feira de Santana, 2015. v.1, p.525-528.

RAMOS, R. R. C.; MANSUR, K. L.; RICARDO, A. M.; IAFFE, A. Pedreira da Ilha do Catalão: registro de antiga lavra de pedrade-cantaria na margem da Baía de Guanabara. In: Congresso Brasileiro de Geologia, 47. Salvador. Anais...Salvador: SBG Núcleo Bahia, 2014. v.1, p.809-809. 
CEA - Companhia Editora Americana. Ilha do Catalão. Revista Eu sei tudo, Vol. 16, setembro de 1918, p. 64.

VIEIRA FILHO, C. L. A.; SATHLER, M. M.; RAMOS, R. R. C.; MANSUR, K. L.; IAFFE, A.; CARVALHO, M. D. S.; SILVA, D. R. L.; BRAGA, L. $P$. Análise geoestatística para identificação da metodologia utilizada na antiga lavra a céu aberto na Ilha do Catalão, Cidade Universitária da UFRJ. In: Congresso Brasileiro de Geologia, 48. Porto Alegre. Anais...Porto Alegre: Sociedade Brasileira de Geologia, 2016. 1p.
Contribuição ao

1‥ Simpósio Brasileiro de Caracterização e Conservação da Pedra 14 a 16 de dezembro de 2016, Congonhas - MG

Nota:

É de responsabilidade da comissão editorial do Simpósio a revisão gramatical, ortográfica, de citações e referências bibliográficas. As normas de submissão podem se diferenciar das desta revista. 